\title{
Moist Air Flow Analysis in an Open Enclosure. Part A: Parametric Study
}

\author{
Tounsi Chati \\ Laboratory of Development in Mechanics and Materials \\ Ziane Achour University of Djelfa \\ Djelfa, Algeria \\ t.chati@univ.djelfa.dz
}

Toufik Tayeb Naas

Gas Turbine Joint Research Team

Ziane Achour University of Djelfa

Djelfa, Algeria

toufiknaas@gmail.com

\author{
Kouider Rahmani \\ Modeling, Simulation and Optimization of Real Complex \\ Systems Research Laboratory,University of Djelfa \\ Djelfa, Algeria \\ kouiderrah2@yahoo.fr \\ Abdelkader Rouibah \\ Modeling, Simulation and Optimization of Real Complex \\ Systems Research Laboratory,University of Djelfa \\ Djelfa, Algeria \\ rouibah_a@yahoo.fr
}

\begin{abstract}
Heat and mass transfer in many systems is widely accomplished by applying natural convection processes due to their low cost, reliability, and easy support. Typical applications include different mechanisms in various fields such as solar energy, solar distillers, stream cooling, etc. This paper examines the turbulent natural convection and mass transfer in an open enclosure for different Aspect Ratios $(A R=0.5,1$, and 2) with humid air. Mass fraction and local Nusselt number were examined to investigate the heat and mass transfer. Heat flux boundary conditions were subjected to the lateral walls, the bottom one was an adiabatic wall while the top area was a free surface. The effects of Rayleigh numbers $(106 \leq R a \leq 108)$ on natural convection and mass flow behavior were analyzed. The governing equations were solved using the CFD Fluent code based on the SIMPLE algorithm. Results showed that a cavity with an aspect ratio of $A R=2$ enhanced the rates of both heat and mass transfer. Maximum heat transfer rates were observed when the Rayleigh number increased due to the more vigorous fluid flow. However, mass transfer improved when the Rayleigh number decreased.
\end{abstract}

Keywords-Rayleigh number; turbulent flow; moist air; CFD; free convection

\section{INTRODUCTION}

Thermal turbulent flow is used in multiple applications of different mechanisms and systems such as solar energy collectors and evaporation, drying, distillation, and cooling processes of electronic compounds [1-9]. Mass and heat transfers induced by temperature and concentration gradients, are generally applied in physical processes that involve the convective and diffusive transport of chemical substances. Thereby, these heat and concentration gradients are considered to assist or oppose the performance of a system, depending on the boundary conditions of a problem. Many researchers tried to analyze extensively solutions on the heat transfer flow within closed or open cavities [10-17]. Some studies used heat flux or temperature gradient fields to the cavity walls as boundary conditions [18-20]. Several investigations and experiments were conducted for various structural configurations, such as rectangular and square cavities [21-25], and non-structure enclosures such as sinusoidal and inclined protuberances [14, 16, 19, 26]. The effects of Rayleigh [17, 24] and Reynolds numbers on the behavior of free, forced, and mixed convection were studied in [24-29]. Furthermore, various studies were conducted on the conditions of mass transfer and heat fluid motion for square cavities and rectangular shapes in a closed system [7, 30-36]. The heat and mass transfer induced by natural convection in a steady-state square cavity was studied in [31], proposing a two-dimensional cavity with different heated walls. The effects of the solute momentum on the rates of heat and mass transfer and Lewis number on fluid motion were investigated, suggesting correlations between the properties of dimensional quantities and rates of thermal and mass transfer. The natural double diffusion convection in a square cavity with horizontal walls was examined in [32], characterizing the mass transfer parameters through the local and global Nusselt and Sherwood numbers on all walls. The $3 \mathrm{D}$ aspect was compared to the $2 \mathrm{D}$ in [37], finding a satisfactory agreement for low values of the Rayleigh number.

Several researchers chose the rectangular configuration area to study the heat and mass transfer in natural convection [3840]. The effect of humidity on the natural heat flow and their characteristics between vertical walls in a differentially heated cavity was discussed in $[4,41,42]$. A CFD study of heat and mass transfer by natural convection in a $2 \mathrm{D}$ area with an air$\mathrm{CO}_{2}$ mixture was presented in [43-44]. The effect of the buoyancy ratio on mass and heat transfer was investigated in [44] for different contexts. The thermal air quality behavior of higher $\mathrm{CO}_{2}$ concentration in the vertical walls was analyzed under assisted and opposite flow conditions, considering different values for the Rayleigh number. The temperature 
gradient inside the cavity for turbulent flow was observed more homogeneous for all flow cases.

The effect of mass on heat transfer with radiation on the double diffusion problems has been examined for Newtonian and non-Newtonian fluids in [45] and [46] respectively concluding that the radiative heat transfer inside the enclosure gave better thermal results and did not affect the mass transfer process. The humid air transfer for natural convection in a $2 \mathrm{D}$ rectangular surface with a solid section was investigated in [35], dealing with a set of different variables: Rayleigh thermal number, partition thickness, inclination, and buoyancy ratio. In [47], the impact of a heated plate on double-diffusive free convection in a square closed cavity was examined. The vertical walls maintained low temperatures while the horizontal walls were adiabatic, and the vortex viscosity values reduced both heat and mass transfer rates. A new vision on the mass transfer behavior of moisture under the buoyancy-driven effect for low turbulent flows was carried out in [35], using different values of mass fraction and varying temperature gradients between 20 and $60^{\circ} \mathrm{C}$. The study concluded that the vapor content in the humid air had an important impact on heat and current fields inside the enclosure, and the variation of the vertical wall temperature gradients showed the effect of moisture concentration inside the cavity. The percentage of the difference in heat transfer changed significantly depending on the mass fraction of air moisture and the heat gradient between the vertical sides. The air-steam mixture flow of the natural convection inside a square cavity with vertical wall temperature and concentration gradients was investigated in [48], proposing a Prandtl number equal to 1.32 and a Rayleigh number equal to $4.05 \times 10^{5}$. The influence of species spread was investigated with Soret and Dufour mixture effects, finding that these effects had little contribution for this binary mixture.

A parametric study of a differentially heated enclosure to treat the natural convection flows that contained a mixture of air and carbon dioxide was conducted in [49], analyzing the effect of change in buoyancy rate on the mass transfer for a laminar system. A new procedure for a solar system was proposed in [3], considering a latent heat source of evaporation condensation in the energy equation. The results proved that the properties were uniformly distributed. The relative humidity was almost $100 \%$ in the whole enclosure which implied that the air was saturated everywhere. However, the sudden change in the temperature or mass fraction was near the evaporating surface. The free convection of thermo-solute with mass lines and thermal flow in a rectangular area was investigated in [36], where the vertical sides were isotherms and the others adiabatic. The study examined Prandtl number, Rayleigh number, buoyancy ratio, and Lewis number, finding that these parameters significantly affect the overall rates of heat and solute transfer. In [50], an experimental study was conducted to examine the combined thermal flow caused by mass transport and buoyancy in an open enclosure for various aspect ratios. The results of retained condensate on mass movement areas due to water's thermal stability were also examined with no remarkable impacts.

In [51], the heat and mass transfer inside a ventilated cavity in laminar flow was examined for fluid of air- $-\mathrm{CO}_{2}$ mixtures. A comparative study was conducted to examine the thermal behavior and the air quality inside a cavity, considering the exit space location of the fluid mixture and three different values for the $\mathrm{CO}_{2}$ contaminant $(1000,2000,3000 \mathrm{ppm})$. The air inlet space was located below the right vertical side of the cavity, and the location of the mixture outlet was considered in four different positions. In [33], double diffusion natural convection for open square enclosures was investigated with constant concentrations and temperatures imposed along the right and the left walls. Results showed that the top thermal flow was the most effective for heat transfer, while the middle heating was the most stable for mass transfer. The effects of buoyancy ratio, Rayleigh number, Soret and Dufour coefficients, and Lewis number on heat and mass transfer in an open cavity were simulated in [52]. The results showed that changing the Lewis number had little influence on Sherwood and Nusselt numbers, but when the Rayleigh number increased Lewis number increased gradually.

Despite the importance of mass transfer flow, there are only a few research efforts on the natural convection of open cavities, especially with moist air as a working fluid. This paper investigates the natural convection inside an open cavity through humid-air passes for turbulent flow to examine the impact of Rayleigh number and aspect ratios on the heat and mass transfer at heat flux subjected to the vertical walls.

\section{MATHEMATICAL MODELING}

\section{A. Geometrical Description}

The considered physical problem is shown schematically in Figure 1. Humid-air occupies a two-dimensional rectangular enclosure. The vertical parallel walls are subjected to uniform flux $(q)$ and the bottom side is considered impermeable and adiabatic. The top domain is defined as a free surface. The dimension of the open fluid at the bottom left wall was equal to $20 \%$ of the enclosure's height. Different cases of aspect ratios $(\mathrm{AR}=H / L=0.5,1$, and 2$)$ were proposed.

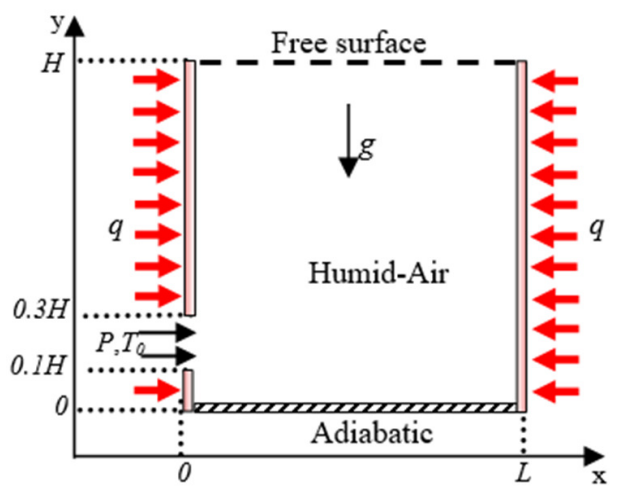

Fig. 1. A schematic representation of an open cavity.

\section{B. Governing Equations}

The governing equations for heat and mass transfer inside this open cavity are the continuity, momentum, energy, and concentration of humid-air liquid equation for natural convection [30]: 
- Continuity equation:

$$
\frac{\partial u}{\partial x}+\frac{\partial v}{\partial y}=0
$$

- Momentum equations:

$$
\begin{gathered}
\frac{\partial u}{\partial t}+u \frac{\partial u}{\partial x}+v \frac{\partial u}{\partial y}=-\frac{1}{\rho} \frac{\partial P}{\partial x}+v\left(\frac{\partial^{2} u}{\partial y^{2}}+\frac{\partial^{2} u}{\partial x^{2}}\right) \\
\frac{\partial v}{\partial t}+u \frac{\partial v}{\partial x}+v \frac{\partial v}{\partial y}=-\frac{1}{\rho} \frac{\partial P}{\partial y}+v\left(\frac{\partial^{2} v}{\partial y^{2}}+\frac{\partial^{2} v}{\partial x^{2}}\right)+g \beta\left(T-T_{0}\right)
\end{gathered}
$$

- Energy equation:

$$
\frac{\partial T}{\partial t}+u \frac{\partial T}{\partial x}+v \frac{\partial T}{\partial y}=\alpha\left(\frac{\partial^{2} T}{\partial x^{2}}+\frac{\partial^{2} T}{\partial y^{2}}\right)
$$

- Concentration equation:

$$
\frac{\partial C}{\partial t}+u \frac{\partial C}{\partial x}+v \frac{\partial C}{\partial y}=D\left(\frac{\partial^{2} C}{\partial x^{2}}+\frac{\partial^{2} C}{\partial y^{2}}\right)
$$

where $v$ is the kinematic viscosity, $\beta$ is the thermal expansion coefficient, $P$ is the fluid pressure, $\alpha$ and $D$ are the thermal and mass diffusivity, respectively. All the governing equations of heat and mass transfer in the proposed open cavity were solved in a turbulent regime using the CFD code. A second-order upwind scheme was selected to solve the concentration and momentum equations. The computations were simulated to be converged at $10^{-7}$ of root mean square residual values.

\section{Turbulence Model}

A standard simple model of turbulence was proposed in [53], named $k-\varepsilon$, which is based on the turbulent kinetic energy equations $k$ and the rate of dissipation of turbulent kinetic energy $\varepsilon$. This model was used to analyze the flow and heat transfer calculations due to its robustness, and consistent precision. The generic form of this model is [16]:

$$
\begin{gathered}
\frac{\partial}{\partial t}(\rho k)+\frac{\partial}{\partial x}(\rho k u)= \\
\frac{\partial}{\partial y}\left[\left(\mu+\frac{\mu_{t}}{\sigma_{k}}\right) \frac{\partial k}{\partial y}\right]+G_{k}+G_{b}-\rho \varepsilon-Y_{M}+S_{k} \\
\frac{\partial}{\partial t}(\rho \varepsilon)+\frac{\partial}{\partial x}(\rho \varepsilon u)=\frac{\partial}{\partial y}\left[\left(\mu+\frac{\mu_{t}}{\sigma_{\varepsilon}}\right) \frac{\partial \varepsilon}{\partial y}\right]+ \\
C_{\varepsilon 1} \cdot \frac{\varepsilon}{k}\left(G_{k}+C_{\varepsilon 3} G_{b}\right)-C_{\varepsilon 2} \rho \frac{\varepsilon^{2}}{k}+S_{\varepsilon}
\end{gathered}
$$

where $\mu_{t}$ is the Eddy viscosity, $\sigma_{k}$ and $\sigma_{\varepsilon}$ are the turbulent Prandtl numbers for $k$ and $\varepsilon, S_{k}$ and $S_{\varepsilon}$ are user-defined source terms, $G_{k}$ represents the kinetic energy production of turbulence due to velocity gradients, $G_{b}$ is the kinetic energy production of turbulence due to buoyancy, $Y_{M}$ represents the contribution of the expansion of fluctuations, $C_{\mu}=0.09$, $C_{\varepsilon 1}=1.44, C_{\varepsilon 2}=1.92, \sigma_{k}=1$, and $\sigma_{\varepsilon}=1.3$.

\section{Boundary Conditions}

The boundary conditions associated with the problem were:
- $x=0 ; 0 \leq y \leq 0.1 H: \quad u=v=0, q=5 w, C=1$

- $x=0 ; 0.1 H \leq y \leq 0.3 H: \quad u=v=0, q=0, \quad C=0$

$$
T=T_{0}, \quad P=P_{0}
$$

- $x=0 ; 0.3 H \leq y \leq H: \quad u=v=0, q=5 w, C=1$

- $x=L ; 0 \leq y \leq H: \quad u=v=0, q=5 w, C=1$

- $y=0 ; 0 \leq x \leq L: \quad u=v=0, \partial T / \partial y=0, \partial C / \partial y=0$

- $y=H ; 0 \leq x \leq L: \quad u=v=0, q=5 w \quad C=0$

$$
T=T_{0}, \quad \Delta P=\rho g H
$$

The following variables are dimensionless:

$$
X^{*}=x / L, \quad Y^{*}=y / L, \quad T^{*}=\left(T-T_{C}\right) /\left(T_{H}-T_{C}\right)
$$

\section{E. Meshing Sensitivity Analysis}

The region was covered with a meshing grid having a further refinement in vertical sides. Different grids were used: $140 \times 140,160 \times 160,180 \times 180$, and $200 \times 200$ for a cavity with aspect ratio $A R=1$. From Table I, it is clear that the $180 \times 180$ mesh produced more satisfactory results than the others, for a maximum error of $0.02 \%$ and maximum values for the velocity components $u$ and $v$.

TABLE I. MESH SENSITIVITY TEST FOR MAXIMUM X, YVELOCITIES, AND TEMPERATURE.

\begin{tabular}{|c|c|c|c|c|}
\hline & $\mathbf{1 4 0} \times \mathbf{1 4 0}$ & $\mathbf{1 6 0 \times 1 6 0}$ & $\mathbf{1 8 0} \times \mathbf{1 8 0}$ & $\mathbf{2 0 0} \times \mathbf{2 0 0}$ \\
\hline $\begin{array}{c}\boldsymbol{u m a x} \\
(\mathbf{m} / \mathbf{s})\end{array}$ & $\begin{array}{c}0.100652 \\
(0.03 \%)\end{array}$ & $\begin{array}{c}0.100668 \\
(0.01 \%)\end{array}$ & $\begin{array}{c}0.100673 \\
(0.00 \%)\end{array}$ & 0.100678 \\
\hline $\boldsymbol{\operatorname { v m a x }}$ & $\begin{array}{c}0.087004 \\
(\mathbf{m} / \mathbf{s})\end{array}$ & $\begin{array}{c}0.086937 \\
(0.05 \%)\end{array}$ & $\begin{array}{c}0.0869814 \\
(0.02 \%)\end{array}$ & 0.086962 \\
\hline $\begin{array}{c}\boldsymbol{T} \boldsymbol{m a x} \\
(\mathbf{K})\end{array}$ & $\begin{array}{c}304.914 \\
(0.005 \%)\end{array}$ & $\begin{array}{c}304.92 \\
(0.003 \%)\end{array}$ & $\begin{array}{c}304.9246 \\
(0.001 \%)\end{array}$ & 304.929 \\
\hline
\end{tabular}

\section{RESULTS AND DISCUSSION}

The effects of aspect ratios ( $A R=0.5,1$ and 2$)$ and Rayleigh number $\left(10^{6} \leq R a \leq 10^{8}\right)$ on heat and mass transfer of turbulent humid-air flow for an open enclosure were investigated parametrically. The thermophysical properties of the working fluid were [54]:

- $\rho_{0}=1.15\left[\mathrm{Kg} \cdot \mathrm{m}^{-3}\right]$

- $C p_{0}=1005\left[\mathrm{~J} \cdot \mathrm{Kg}^{-1} \cdot \mathrm{K}^{-1}\right]$

- $\lambda_{0}=2 \cdot 65 \cdot 10^{-2}\left[\mathrm{~W} \cdot \mathrm{m}^{-1} \cdot \mathrm{s}^{-1}\right]$

- $\mu_{0}=1.85 \cdot 10^{-5}\left[\mathrm{Kg} \cdot \mathrm{m}^{-1} \cdot \mathrm{s}^{-1}\right]$

- $D=2.59 \cdot 10^{-5}\left[\mathrm{~m}^{2} \cdot \mathrm{s}^{-1}\right]$.

\section{A. Validation}

The flow visualization of isotherms, streamlines, and isoconcentration results for the heat and mass transfer $\left(R a=10^{7}\right.$ with different buoyancy ratios) were compared with those obtained by [49], as shown in Figure 2. A second validation was investigated with results from $[31,37,51]$, concerning the Nusselt number as a function of the buoyancy ratio $(N)$. The validations were satisfactory exhibiting good agreement, as shown in Table II. 


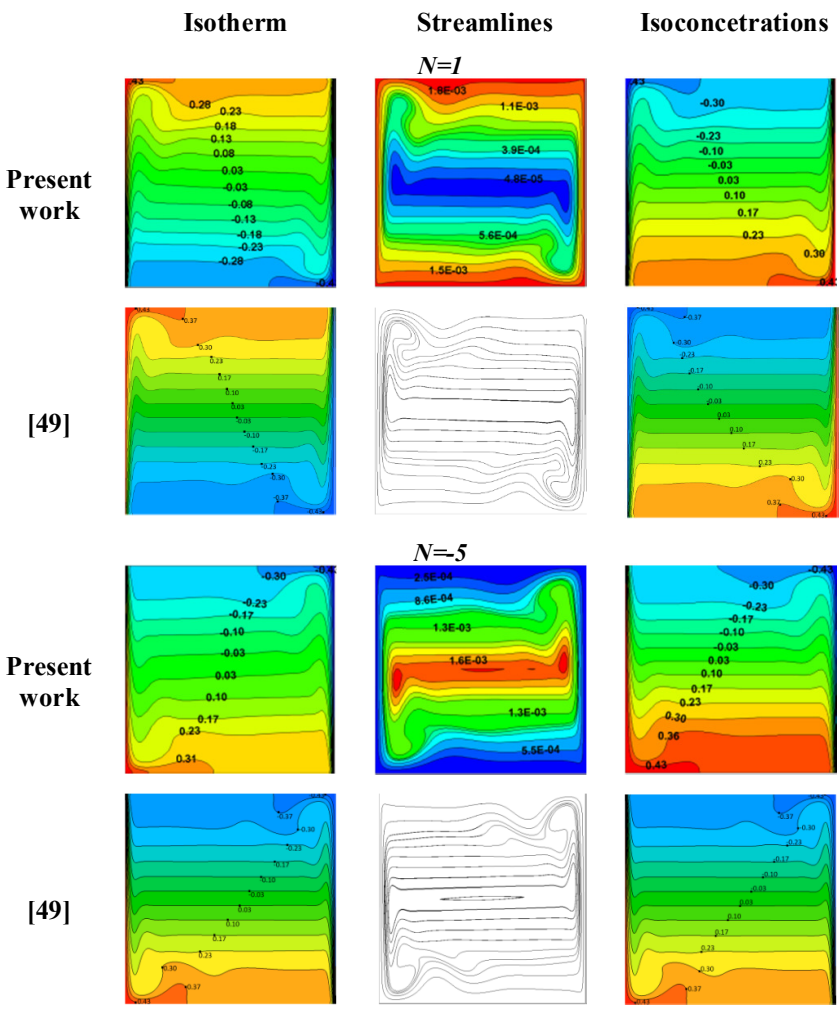

Fig. 2. Qualitative validation: Comparison of isotherm, streamline and iso-concentration contours for $R a=10^{7}$ and $N=1$ and -5 .

TABLE II. QUANTITATIVE VALIDATION; NUSSELT NUMBER AS FUNCTION OF BUOY ANCY RATIO.

\begin{tabular}{|c|c|c|c|}
\hline \multicolumn{4}{|c|}{$\boldsymbol{N u}$} \\
\hline $\boldsymbol{N}$ & $\mathbf{- 0 . 5}$ & $\mathbf{- 0 . 8}$ & $\mathbf{- 5 . 0}$ \\
\hline Present work & 13.6 & 10.3 & 23.2 \\
\hline$[\mathbf{5 1}]$ & 13.6 & 10.6 & 23.7 \\
\hline$[\mathbf{3 7}]$ & 13.5 & 10.5 & 23.5 \\
\hline$[\mathbf{3 1}]$ & 13.6 & 10.6 & 23.7 \\
\hline Err \% for [51] & $0.7 \%$ & $1.9 \%$ & $1.2 \%$ \\
\hline
\end{tabular}

\section{B. Discussion}

Isotherms, streamlines, and mass fraction of $\mathrm{H}_{2} \mathrm{O}$ visualizations are illustrated in Figures 3, 4, and 5 to examine the hydrodynamic behavior and the heat transfer characteristics for $A R=0.5,1$, and 2 , respectively. The main flow tended to cross the cavity in a semi-vertical direction, creating a strong vortex at the bottom right wall of each configuration and indicating an accelerating mass transfer. The heat transfer efficiency for the natural convection of humid-air inside open enclosures was influenced by the Rayleigh number at the lateral walls for all aspect ratios. For $A R=0.5$, the small cell found at the middle of the free surface was lost by the effect of enhanced buoyancy forces. Another clockwise small rotating vortex was created at the left bottom wall, where its size became increasingly powerful, while the high temperatures were localized in close spaces near the humid left wall, which corresponded to the concentration of the thermal boundary layer. For the square enclosure, three cells started to develop compared to $A R=2$ geometries. The contours of the $\mathrm{H}_{2} \mathrm{O}$ mass fraction for all aspect ratios showed that the mass transfer dominated more as the Rayleigh number decreased. A close observation of the isotherms and hydrodynamics contours remarks that the mass and heat transfer processes were less concentrated at the top free surface. The concentration of $\mathrm{H}_{2} \mathrm{O}$ increased significantly on the left wall of the enclosure, especially for $A R=2$.

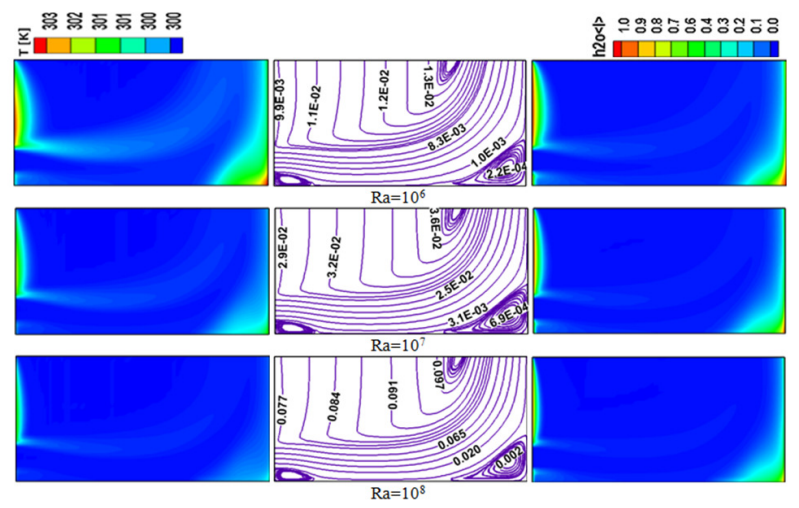

Fig. 3. Contours of isotherms (left), streamlines (middle), and mass fraction of $\mathrm{H}_{2} \mathrm{O}$ liquid (right) at $A R=0.5$ for different Rayleigh numbers $\left(10^{6} \leq R a \leq 10^{8}\right)$.

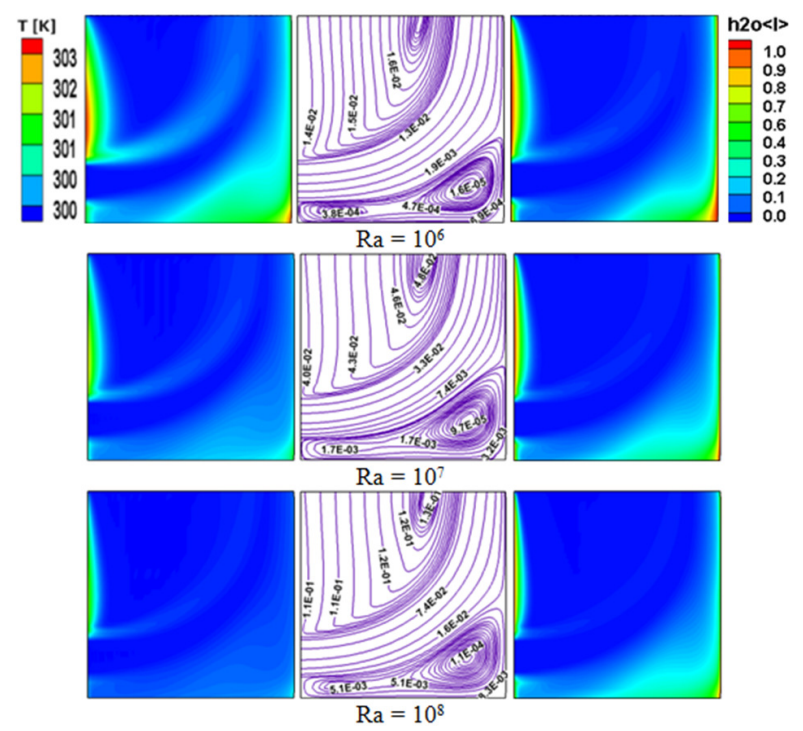

Fig. 4. Contours of isotherms (left), streamlines (middle), and mass fraction of $\mathrm{H}_{2} \mathrm{O}$ liquid (right) at $A R=1$ for different Rayleigh numbers $\left(10^{6} \leq R a \leq 10^{8}\right)$.

The effect of the Rayleigh number with a fixed wall heat flux on the enhancement of thermal flow and mass transfer are presented in Figures 6 and 7 respectively. The local Nusselt number and mass fraction indicate the efficiency of the heat and mass transfer processes. As the height of the cavity has a significate role, the greater heat and mass transfers were found at $A R=2$. For low values of the Rayleigh number, the mass fraction of the humid-air increased while the Nusselt number decreased due to the slowly moving fluid. The heat transfer increased with the Rayleigh number, showing optimum thermal performance due to the vigorous turbulent flow. 


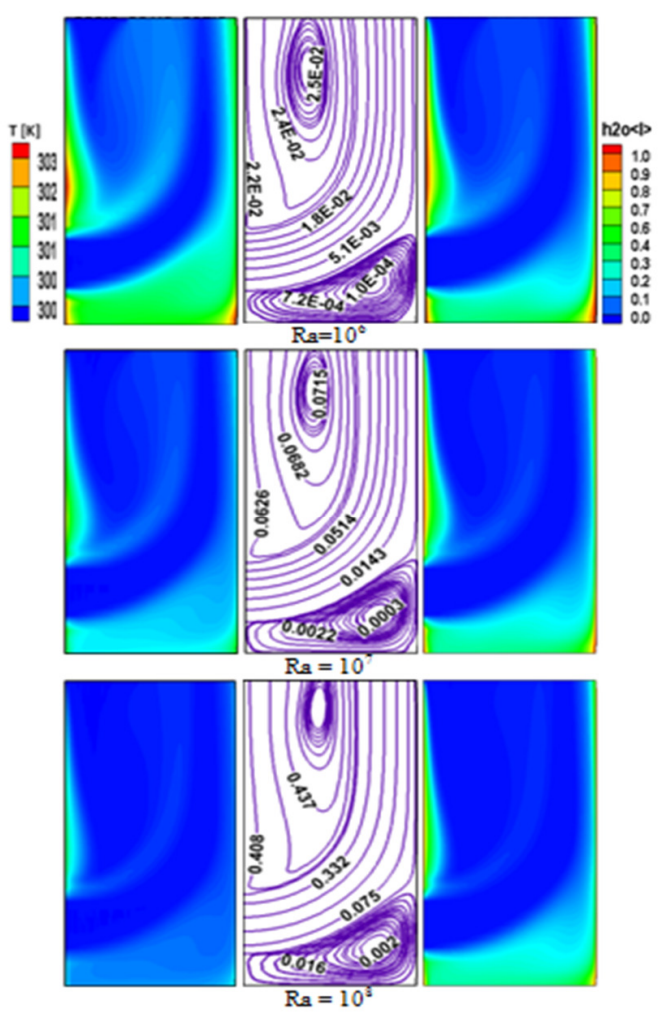

Fig. 5. Contours of isotherms (left), streamlines (middle), and mass fraction of $\mathrm{H}_{2} \mathrm{O}$ liquid (right) at $A R=2$ for different Rayleigh numbers $\left(10^{6} \leq R a \leq 10^{8}\right)$.

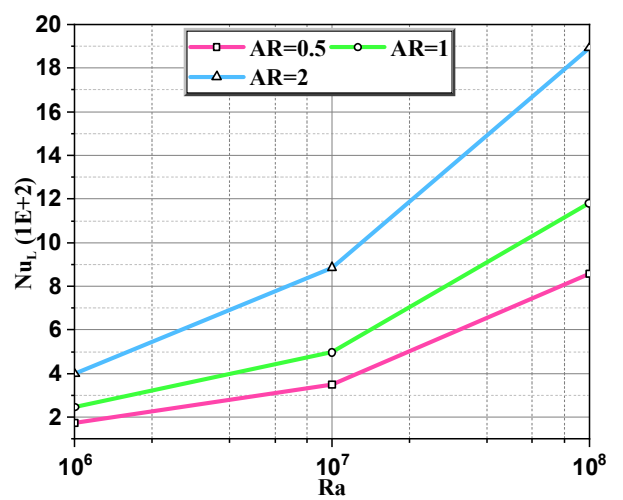

Fig. 6. Evolution of local Nusselt number as a function of Rayleigh number with different aspect ratios $(A R=0.5,1$, and 2$)$.

\section{CONCLUSIONS}

This paper examined the effective mass and heat transfer efficiency for the natural convection of humid air inside open enclosures, concluding the following:

- Heat transfer efficiency for natural convection of humid air inside open enclosures is influenced by the Rayleigh number at the lateral walls for all aspect ratio cases. The mass transfer decreases because of vaporization. Moreover, as the Rayleigh number increased the flow visualization revealed that the vortex created in each enclosure had more vigorous intensity.

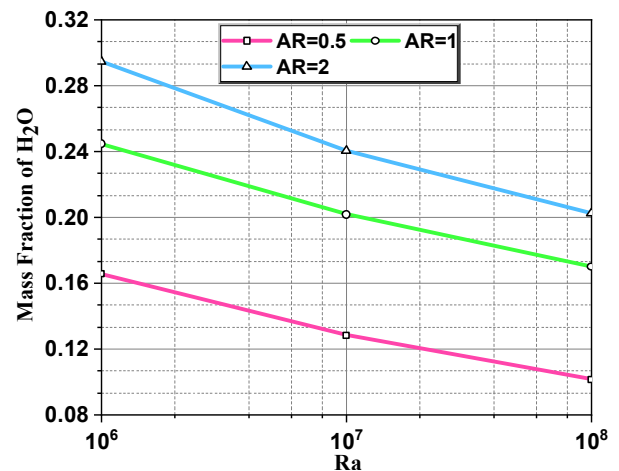

Fig. 7. Mass fraction of $\mathrm{H}_{2} \mathrm{O}$ for various Rayleigh numbers with different aspect ratios $(A R=0.5,1$, and 2$)$.

- The opening surface enhanced the mass transfer, while the bottom wall was the most stable for a few mass transfers.

- The mass transfer was reduced for the square cavity compared to the preferable enclosure at aspect ratio $A R=2$. Furthermore, higher rates of the Rayleigh number increased the thermal enhancement rate and decreased the mass fraction of humid air.

- As a consequence, the thermal and mass transfer performance in the cavity with $A R=2$ was greater than in the other configurations for moist air as a working fluid.

\section{ACKNOWLEDGMENT}

This research was funded by the Ministry of Higher Education and Scientific Research, Algeria

\section{REFERENCES}

[1] M. M. Rahman, H. F. Öztop, A. Ahsan, M. A. Kalam, and Y. Varol, "Double-diffusive natural convection in a triangular solar collector," International Communications in Heat and Mass Transfer, vol. 39, no. 2, pp. 264-269, Feb. 2012, https://doi.org/10.1016/j.icheatmasstransfer. 2011.11.008.

[2] W. Aich, "3D Buoyancy Induced Heat Transfer in Triangular Solar Collector Having a Corrugated Bottom Wall," Engineering, Technology \& Applied Science Research, vol. 8, no. 2, pp. 2651-2655, Apr. 2018, https://doi.org/10.48084/etasr.1857.

[3] M. Keshtkar, M. Eslami, and K. Jafarpur, "A novel procedure for transient CFD modeling of basin solar stills: Coupling of species and energy equations," Desalination, vol. 481, May 2020, Art. no. 114350, https://doi.org/10.1016/j.desal.2020.114350.

[4] H. Sun, G. Lauriat, and X. Nicolas, "Natural convection and wall condensation or evaporation in humid air-filled cavities subjected to wall temperature variations," International Journal of Thermal Sciences, vol. 50, no. 5, pp. 663-679, May 2011, https://doi.org/10.1016/j.ijthermalsci. 2010.12 .010 .

[5] N. Alleborn, H. Raszillier, and F. Durst, "Lid-driven cavity with heat and mass transport," International Journal of Heat and Mass Transfer, vol. 42, no. 5, pp. 833-853, Mar. 1999, https://doi.org/10.1016/S00179310(98)00224-5.

[6] L. B. Snoussi, R. Chouikh, and A. Guizani, "Numerical study of the natural convection flow resulting from the combined buoyancy effects of thermal and mass diffusion in a cavity with differentially heated side walls," Desalination, vol. 182, no. 1, pp. 143-150, Nov. 2005, https://doi.org/10.1016/j.desal.2005.03.014.

[7] R. Alvarado-Juárez, G. Álvarez, J. Xamán, and I. Hernández-López, "Numerical study of conjugate heat and mass transfer in a solar still device," Desalination, vol. 325, pp. 84-94, Sep. 2013, https://doi.org/ 10.1016/j.desal.2013.06.027. 
[8] K. B. Saleem, L. Koufi, A. K. Alshara, and L. Kolsi, "Double-diffusive natural convection in a solar distiller with external fluid stream cooling," International Journal of Mechanical Sciences, vol. 181, Art. no. 105728, Sep. 2020, https://doi.org/10.1016/j.ijmecsci.2020.105728.

[9] T. Ikeshoji, F. N. B. de Nahui, S. Kimura, and M. Yoneya, "Computer analysis on natural convection in thin-layer thermocells with a soluble redox couple: Part 2. E-I relation, electric power, heat flux and electrochemical heat pump," Journal of Electroanalytical Chemistry and Interfacial Electrochemistry, vol. 312, no. 1, pp. 43-56, Aug. 1991, https://doi.org/10.1016/0022-0728(91)85143-D.

[10] M. N. Hasan, S. C. Saha, and Y. T. Gu, "Unsteady natural convection within a differentially heated enclosure of sinusoidal corrugated side walls," International Journal of Heat and Mass Transfer, vol. 55, no. 21, pp. 5696-5708, Oct. 2012, https://doi.org/10.1016/j.ijheatmasstransfer. 2012.05.065.

[11] M. M. El-Gendi and A. M. Aly, "Numerical simulation of natural convection using unsteady compressible Navier-stokes equations," International Journal of Numerical Methods for Heat \& Fluid Flow, vol. 27, no. 11, pp. 2508-2527, Jan. 2017, https://doi.org/10.1108/ HFF-10-2016-0376.

[12] I. Kouroudis, P. Saliakellis, and S. G. Yiantsios, "Direct numerical simulation of natural convection in a square cavity with uniform heat fluxes at the vertical sides: Flow structure and transition," International Journal of Heat and Mass Transfer, vol. 115, pp. 428-438, Dec. 2017, https://doi.org/10.1016/j.ijheatmasstransfer.2017.08.058.

[13] A. Fabregat and J. Pallarès, "Heat transfer and boundary layer analyses of laminar and turbulent natural convection in a cubical cavity with differently heated opposed walls," International Journal of Heat and Mass Transfer, vol. 151, Apr. 2020, Art. no. 119409, https://doi.org/10.1016/j.ijheatmasstransfer.2020.119409.

[14] M. Prakash, S. B. Kedare, and J. K. Nayak, "Numerical study of natural convection loss from open cavities," International Journal of Thermal Sciences, vol. 51, pp. 23-30, Jan. 2012, https://doi.org/10.1016/ j.ijthermalsci.2011.08.012.

[15] B. Zamora and A. S. Kaiser, "Influence of the variable thermophysical properties on the turbulent buoyancy-driven airflow inside open square cavities," Heat and Mass Transfer, vol. 48, no. 1, pp. 35-53, Jan. 2012, https://doi.org/10.1007/s00231-011-0838-0.

[16] K. Rahmani, A. Bentebbiche, and B. Draoui, "Numerical Investigation of Turbulent Natural Convection for a Cavity Having Sinusoidal Protuberances on a Vertical Wall," Journal of Applied Fluid Mechanics, vol. 6, no. 04, pp. 491-199, Oct. 2013, https://doi.org/10.36884/ jafm.6.04.21278.

[17] R. Choudhary, A. Saini, and S. Subudhi, "Oberbeck-Boussinesq approximations and geometrical confinement effects of free convection in open cavity," Heat and Mass Transfer, vol. 55, no. 8, pp. 2095-2102, Aug. 2019, https://doi.org/10.1007/s00231-019-02563-8.

[18] V. M. Maytorena, A. Piña-Ortiz, and J. F. Hinojosa, "Experimental and numerical study of turbulent natural convection in an open cubic cavity," Heat and Mass Transfer, vol. 51, no. 9, pp. 1205-1217, Sep. 2015, https://doi.org/10.1007/s00231-014-1492-0.

[19] T. T. Naas, Y. Lasbet, and C. Kezrane, "Entropy Generation Analyze Due to the Steady Natural Convection of Newtonian Fluid in a Square Enclosure," International Journal of Mechanical and Mechatronics Engineering, vol. 9, no. 4, pp. 582-586, Mar. 2015.

[20] D. Saury, N. Rouger, F. Djanna, and F. Penot, "Natural convection in an air-filled cavity: Experimental results at large Rayleigh numbers," International Communications in Heat and Mass Transfer, vol. 38, no. 6, pp. 679-687, Jul. 2011, https://doi.org/10.1016/j.icheatmasstransfer. 2011.03.019.

[21] Y. S. Tian and T. G. Karayiannis, "Low turbulence natural convection in an air filled square cavity: Part I: the thermal and fluid flow fields," International Journal of Heat and Mass Transfer, vol. 43, no. 6, pp. 849-866, Mar. 2000, https://doi.org/10.1016/S0017-9310(99)00199-4.

[22] Y. S. Tian and T. G. Karayiannis, "Low turbulence natural convection in an air filled square cavity: Part II: the turbulence quantities," International Journal of Heat and Mass Transfer, vol. 43, no. 6, pp. 867-884, Mar. 2000, https://doi.org/10.1016/S0017-9310(99)00200-8.
[23] F. Ampofo and T. G. Karayiannis, "Experimental benchmark data for turbulent natural convection in an air filled square cavity," International Journal of Heat and Mass Transfer, vol. 46, no. 19, pp. 3551-3572, Sep. 2003, https://doi.org/10.1016/S0017-9310(03)00147-9.

[24] A. Vasiliev et al., "High Rayleigh number convection in a cubic cell with adiabatic sidewalls," International Journal of Heat and Mass Transfer, vol. 102, pp. 201-212, Nov. 2016, https://doi.org/10.1016/ j.ijheatmasstransfer.2016.06.015.

[25] Z. Altaç and N. Uğurlubilek, "Assessment of turbulence models in natural convection from two- and three-dimensional rectangular enclosures," International Journal of Thermal Sciences, vol. 107, pp. 237-246, Sep. 2016, https://doi.org/10.1016/j.ijthermalsci.2016.04.016.

[26] A. Latreche and M. Djezzar, "Numerical Study of Natural Convective Heat and Mass Transfer in an Inclined Porous Media," Engineering, Technology \& Applied Science Research, vol. 8, no. 4, pp. 3223-3227, Aug. 2018, https://doi.org/10.48084/etasr.2179.

[27] Y. Varol and H. F. Oztop, "Free convection in a shallow wavy enclosure," International Communications in Heat and Mass Transfer, vol. 33, no. 6, pp. 764-771, Jul. 2006, https://doi.org/10.1016/ j.icheatmasstransfer.2006.02.004.

[28] M. El-Gendi, "Transient turbulent simulation of natural convection flows induced by a room heater," International Journal of Thermal Sciences, vol. 125 , pp. 369-380, Mar. 2018, https://doi.org/10.1016/j.ijthermalsci. 2017.12.012.

[29] L. Koufi, Z. Younsi, Y. Cherif, and H. Naji, "Numerical investigation of turbulent mixed convection in an open cavity: Effect of inlet and outlet openings," International Journal of Thermal Sciences, vol. 116, pp. 103117, Jun. 2017, https://doi.org/10.1016/j.ijthermalsci.2017.02.007.

[30] V. Sévéléder and J. P. Petit, "Flow Structures Induced by Opposing Forces in Double-Diffusive Natural Convection in a Cavity," Numerical Heat Transfer, Part A: Applications, vol. 15, no. 4, pp. 431-444, Jun. 1989, https://doi.org/10.1080/10407788908944697.

[31] C. Béghein, F. Haghighat, and F. Allard, "Numerical study of doublediffusive natural convection in a square cavity," International Journal of Heat and Mass Transfer, vol. 35, no. 4, pp. 833-846, Apr. 1992, https://doi.org/10.1016/0017-9310(92)90251-M.

[32] V. A. F. Costa, "Double diffusive natural convection in a square enclosure with heat and mass diffusive walls," International Journal of Heat and Mass Transfer, vol. 40, no. 17, pp. 4061-4071, Oct. 1997, https://doi.org/10.1016/S0017-9310(97)00061-6.

[33] N. Arbin and I. Hashim, "Partial heating and partial salting on doublediffusive convection in an open cavity," AIP Conference Proceedings, vol. 1614, no. 1, pp. 891-897, Sep. 2014, https://doi.org/10.1063/ 1.4895320 .

[34] J.-T. Hu, X.-H. Ren, D. Liu, F.-Y. Zhao, and H.-Q. Wang, "Natural convective heat and moisture transfer in an inclined building enclosure with one slender wall of finite thickness: Analytical investigation and non-unique steady flow solutions," International Journal of Heat and Mass Transfer, vol. 104, pp. 1160-1176, Jan. 2017, https://doi.org/10.1016/j.ijheatmasstransfer.2016.09.033.

[35] D. Iyi and R. Hasan, "Numerical investigation of the effect of moisture on buoyancy-driven low turbulence flow in an enclosed cavity," International Journal of Heat and Mass Transfer, vol. 136, pp. 543-554, Jun. 2019, https://doi.org/10.1016/j.ijheatmasstransfer.2019.02.102.

[36] D. Kushawaha, S. Yadav, and D. K. Singh, "Thermo-solute natural convection with heat and mass lines in a uniformly heated and soluted rectangular enclosure for low Prandtl number fluids," International Journal of Thermal Sciences, vol. 148, Art. no. 106160, Feb. 2020, https://doi.org/10.1016/j.ijthermalsci.2019.106160.

[37] I. Sezai and A. A. Mohamad, "Double diffusive convection in a cubic enclosure with opposing temperature and concentration gradients," Physics of Fluids, vol. 12, no. 9, pp. 2210-2223, Sep. 2000, https://doi.org/10.1063/1.1286422.

[38] Jae Min Hyun and J. W. Lee, "Double-diffusive convection in a rectangle with cooperating horizontal gradients of temperature and concentration," International Journal of Heat and Mass Transfer, vol. 33, no. 8, pp. 1605-1617, Aug. 1990, https://doi.org/10.1016/00179310(90)90017-O. 
[39] J. W. Lee and Jae Min Hyun, "Double-diffusive convection in a rectangle with opposing horizontal temperature and concentration gradients," International Journal of Heat and Mass Transfer, vol. 33, no. 8 , pp. 1619-1632, Aug. 1990, https://doi.org/10.1016/00179310(90)90018-P.

[40] Jin Wook Lee and Jae Min Hyun, "Time-dependent double diffusion in a stably stratified fluid under lateral heating," International Journal of Heat and Mass Transfer, vol. 34, no. 9, pp. 2409-2421, Sep. 1991, https://doi.org/10.1016/0017-9310(91)90065-M.

[41] O. Laguerre, S. Benamara, D. Remy, and D. Flick, "Experimental and numerical study of heat and moisture transfers by natural convection in a cavity filled with solid obstacles," International Journal of Heat and Mass Transfer, vol. 52, no. 25, pp. 5691-5700, Dec. 2009, https://doi.org/10.1016/j.ijheatmasstransfer.2009.07.028.

[42] O. Laguerre, S. Benamara, and D. Flick, "Numerical simulation of simultaneous heat and moisture transfer in a domestic refrigerator," International Journal of Refrigeration, vol. 33, no. 7, pp. 1425-1433, Nov. 2010, https://doi.org/10.1016/j.ijrefrig.2010.04.010.

[43] J. Serrano-Arellano, J. Xamán, G. Álvarez, and M. Gijón-Rivera, "Heat and mass transfer by natural convection in a square cavity filled with a mixture of Air-CO2," International Journal of Heat and Mass Transfer, vol. 64, pp. 725-734, Sep. 2013, https://doi.org/10.1016/ j.ijheatmasstransfer.2013.05.038.

[44] R. Nikbakhti and A. B. Rahimi, "Double-diffusive natural convection in a rectangular cavity with partially thermally active side walls," Journal of the Taiwan Institute of Chemical Engineers, vol. 43, no. 4, pp. 535541, Jul. 2012, https://doi.org/10.1016/j.jtice.2012.02.010.

[45] J. Serrano-Arellano and M. Gijón-Rivera, "Conjugate heat and mass transfer by natural convection in a square cavity filled with a mixture of Air-CO2," International Journal of Heat and Mass Transfer, vol. 70, pp. 103-113, Mar. 2014, https://doi.org/10.1016/j.ijheatmasstransfer. 2013.10.051.

[46] GH. R. Kefayati, "Simulation of double diffusive natural convection and entropy generation of power-law fluids in an inclined porous cavity with Soret and Dufour effects (Part I: Study of fluid flow, heat and mass transfer)," International Journal of Heat and Mass Transfer, vol. 94, pp. 539-581, Mar. 2016, https://doi.org/10.1016/j.ijheatmasstransfer.2015. 11.044 .

[47] M. Muthtamilselvan, K. Periyadurai, and D. H. Doh, "Impact of nonuniform heated plate on double-diffusive natural convection of micropolar fluid in a square cavity with Soret and Dufour effects," Advanced Powder Technology, vol. 29, no. 1, pp. 66-77, Jan. 2018, https://doi.org/10.1016/j.apt.2017.10.012.

[48] N. Jiang, E. Studer, and B. Podvin, "Physical modeling of simultaneous heat and mass transfer: species interdiffusion, Soret effect and Dufour effect," International Journal of Heat and Mass Transfer, vol. 156, Aug. 2020, Art. no. 119758, https://doi.org/10.1016/j.ijheatmasstransfer. 2020.119758.

[49] L. Koufi, Y. Cherif, Z. Younsi, and H. Naji, "Double-Diffusive Natural Convection in a Mixture-Filled Cavity with Walls' Opposite Temperatures and Concentrations," Heat Transfer Engineering, vol. 40, no. 15 , pp. 1268-1285, Sep. 2019, https://doi.org/10.1080/01457632. 2018.1460928.

[50] W. Terrell and T. A. Newell, "Experimental techniques for determining heat and mass transfer due to condensation of humid air in cooled, open cavities," Applied Thermal Engineering, vol. 27, no. 8, pp. 1574-1584, Jun. 2007, https://doi.org/10.1016/j.applthermaleng.2006.09.022.

[51] J. Xamán, A. Ortiz, G. Álvarez, and Y. Chávez, "Effect of a contaminant source (CO2) on the air quality in a ventilated room," Energy, vol. 36, no. 5, pp. 3302-3318, May 2011, https://doi.org/10.1016/j.energy. 2011.03.026.

[52] Z. Zhou, Z. Wang, and M. Yang, "Double Diffusive Natural Convection in Open Cavity Under the Soret and Dufour Effects," Frontiers in Heat and Mass Transfer (FHMT), vol. 14, Feb. 2020.

[53] B. E. Launder and D. B. Spalding, Lectures in mathematical models of turbulence. New York, NY, USA: Academic Press, 1972.

[54] B. E. Poling, J. M. Prausnitz, and J. P. O'Connell, Properties of Gases and Liquids, Fifth Edition, 5th ed. New York, NY, USA: McGraw-Hill Education, 2001. 